\title{
Full Breastfeeding and Obesity in Children: A Prospective Study from Birth to 6 Years
}

\author{
Juan Antonio Ortega-García, MD, PhD,' Nicole Kloosterman, MSc,' \\ Lizbeth Alvarez, MPH,' Esther Tobarra-Sánchez, MD! \\ Alberto Cárceles-Álvarez, MD, MPH,' Rebeca Pastor-Valero, MSc,' \\ Fernando Antonio López-Hernández, PhD, \\ Manuel Sánchez-Solis, MD, PhD, and Luz Claudio, $\mathrm{PhD}^{3}$
}

\section{Abstract}

Background: Obesity is a major public health crisis among both children and adults and contributes to significant physical, psychological, and economic burden. We aim to investigate the effect of duration of breastfeeding on excessive weight and obesity at 6 years of age.

Subjects/Methods: Data on breastfeeding and child anthropometric measurements were collected in a birth-cohort study in Murcia, Spain $(n=350)$. Breastfeeding status and body mass index (BMI) were established according to WHO definitions. Other factors potentially related to children's weight were considered. Multiple log-linear and ordinal regressions were used to analyze the effects of breastfeeding on overweight and obesity when considering potential confounders.

Results: $33 \%$ and $17.3 \%$ of children in the study were of excess weight and obesity, respectively. Univariate predictors of BMI in children aged 6 were as follows: pregestational maternal BMI $\left(\mathrm{kg} / \mathrm{m}^{2}\right)\left(R^{2}=0.127, p<0.01\right)$; full breastfeeding (weeks) $\left.R^{2}=-0.035, p<0.01\right)$; infant weight gain $(\mathrm{kg})\left(R^{2}=0.348, p<0.01\right)$; and maternal alcohol consumption during pregnancy $(\mathrm{g} /$ day $)\left(R^{2}=0.266, p<0.01\right)$ at age 6 . In the ordinal logistic regression, full breastfeeding was associated with a significant decrease in obesity -0.052 (95\% CI, -0.10 to -0.003$)$.

Conclusions: The delay of bottle feeding introduction may have a protective effect against obesity at 6 years of age. Our findings reinforce the need for greater support of breastfeeding and to promote a healthy environment and antipoverty interventions during pregnancy and infancy, alongside other strategies for obesity prevention.

Keywords: breastfeeding; childhood obesity; childhood overweight; cohort study; Spain

\section{Introduction}

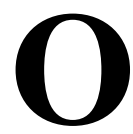
besity is a major public health crisis among both children and adults and contributes to significant physical, psychological, and economic burden. ${ }^{1}$ The prevalence of childhood obesity is increasing in both low- and high-income countries., ${ }^{2,3}$ In 2010, around one in three children in the EU aged 6-9 years were overweight or obese and rates have been increasing since. ${ }^{4}$ In Spain from 2011 to 2012, the prevalence of childhood excess weight and obesity was $29.7 \%$ and $9 \%$, respectively. ${ }^{5}$ Obesity at an early age often continues into adulthood and confers a major risk for insulin resistance, impaired glucose tolerance, hypertension, dyslipidemia, cardiovascular disease, and cancer. ${ }^{6-9}$

A mounting body of evidence suggests that breastfeeding may also play a role in programming noncommunicable disease risk later in life. Evidence in the literature analyzing the protective effects of breastfeeding against childhood adiposity has yielded controversial conclusions. Some studies

\footnotetext{
'Pediatric Environmental Health Speciality Unit, Laboratory of Environmental and Human Health (A5), Department of Paediatrics, Institute of Biomedical Research, IMIB-Arrixaca, Virgen de la Arrixaca University Hospital, University of Murcia, Murcia, Spain. ${ }^{2}$ Departamento de Métodos Cuantitativos e Informáticos. Universidad Politécnica de Cartagena, Cartagena, Spain. ${ }^{3}$ Division of International Health, Mount Sinai School of Medicine, New York, NY.
}

(C) Juan Antonio Ortega-García et al., 2018; Published by Mary Ann Liebert, Inc. This Open Access article is distributed under the terms of the Creative Commons License (http://creativecommons.org/licenses/by/4.0), which permits unrestricted use, distribution, and reproduction in any medium, provided the original work is properly credited. 
have found no significant correlation between breastfeeding and different measures of overweight. ${ }^{10,11}$ However, other authors have found that children who had not been breastfed $^{12,13}$ or who were breastfed for a shorter period of time ${ }^{14,15}$ showed increased risk of overweight and obesity. Table $1^{6-8,10-24}$ describes various cohort studies on this topic. Identifying modifiable determinants of childhood obesity, such as breastfeeding, are critical for developing effective intervention strategies for this chronic disease.

The mechanisms underlying the association between breastfeeding and obesity highlight three protective effects which may lead to lower body fat levels in breastfed infants. Breastfeeding helps encourage self-regulation of intake, reduce interference of caregivers in creating positive feeding behaviors, and providing necessary chemical components to regulate energy metabolism. ${ }^{25}$ Human milk contains hormones that moderate energy metabolism and food intake. Various hormones, including leptin, insulin, adiponectin, and obestatin, can activate various pathways that regulate hunger, depending on energy requirements, possibly also via epigenetic processes ${ }^{26,27}$ Also, the beneficial effects of breastfeeding on obesity could be mediated partly by programming a healthier composition of gut microbiome, inducted by some breast milk components (nondigestible oligosaccharides) ${ }^{28}$ Differences in hormone and protein content between breast milk and formula may play a role in increasing risk of excess weight and obesity. ${ }^{26}$ Also, recommendations have been made to study mode of administration and its impact on childhood obesity to determine its role in appetite regulation regardless of substance consumed. ${ }^{15}$

This article uses the MALAMA (Medio Ambiente y Lactancia Materna) longitudinal population-based cohort to analyze the relationship between breastfeeding and childhood outcomes. ${ }^{29,30}$ In this study, we examined the relationship between the duration of breastfeeding and body mass index (BMI) at 6 years of age in a Mediterranean Region, accounting for other factors that influence obesity.

\section{Materials and Methods}

\section{Study Participants}

Murcia is a European region located in southeast Spain, with a total population of $1,472,000$ inhabitants $(259,083<15$ years) in $2013 .{ }^{31}$ The study was conducted within four health areas $(1,6,7$, and 9$)$ whose reference maternity hospital is the Clinical University Hospital "Virgen de la Arrixaca" with a reference population of 747,233 persons and 8150 newborns per year.

MALAMA is an ongoing longitudinal, prospective cohort study from birth until 18 years of age that examines the relationship between breastfeeding duration and childhood development. The MALAMA project follows 430 mother-child pairs, from two population-based birth cohorts. ${ }^{29,30,32}$ This study was based on the second de novo MALAMA cohort, where 350 mother-child pairs were randomly selected one out of two after giving birth at Clinical University Hospital "Virgen de la Arrixaca" be- tween June 10 and July 20, 2009. ${ }^{30,32}$ The central location of the maternity hospital facilitates ease of access to cohort for follow-up for all newborns and family in the study. The MALAMA project was approved by the Ethics Committee and the Institutional Review Board of the Clinical University Hospital "Virgen de la Arrixaca."

The participants included in this study were healthy newborns born full-term ( $>37$ weeks of gestation), weighing $>2500 \mathrm{~g}$ at the study hospital, first born, and with Apgar test given at 1 minute and 5 minutes with a minimum score of 7 and 8, respectively. Participants were excluded from the study if a telephone number was unavailable to contact the parents, newborns were admitted to the neonatal unit during the first 48 hours, and a linguistic barrier was present that was unable to be overcome either due to the lack of an available interpreter or the inability to hold a conversation.

Recruitment and the first interview were conducted faceto-face with either the mother or both parents present at the time of neonatal discharge. In addition, face-to-face interviews were conducted at both the first month and the 24 th month. They were interviewed by a nurse trained in breastfeeding and research methodology, utilizing a carefully developed questionnaire known as "la hoja verde" or the "green page" (GP). GP on reproductive environmental health includes the standard clinical record of pregnant or lactant women and constitutes a series of concise and basic question through which the healthcare professional identifies environmental exposure during these periods. ${ }^{33-35}$ Follow-up was done through a series of phone calls at 1, 3, 6 , and 12 months. Up to five phone calls were placed to establish contact with the study participants before lost to follow-up. A scheduled well-child care physical examination includes anthropometric measures at 1, 2, 4, and 6 years old. The anthropometric measurements of children at 6 years were obtained from a growth monitoring program within the pediatric primary care unit from the child ambulatory history. Well-child visit programs are an important tool utilized by healthcare providers to screen for medical and developmental issues. ${ }^{36}$

From the 350 mother-newborn dyads randomly recruited, 15 did not meet the inclusion criteria and 327 dyads (97.6\%) agreed to participate in the study. There were three couples $(1 \%)$ who were lost to follow-up at 1 year and 1 $(0.3 \%)$ that abandoned the study at 1 year. Of the remaining children, 324 provided information regarding full breastfeeding, and information regarding BMI at 6-year mark was available in 231 (71.3\%) children for the study.

\section{Infant Feeding Practice}

Data were collected on breastfeeding, as defined by the World Health Organization (WHO) recommendations. "Exclusive breastfeeding" (EBF) means that the infant receives only breast milk, no other liquids or solids are given, and "Full breastfeeding" (FBF) includes exclusive (no other liquid or solid is given to the infant) and almost exclusive (vitamins, mineral water, juice, or ritualistic feeds are given infrequently in addition to breastfeeds or 


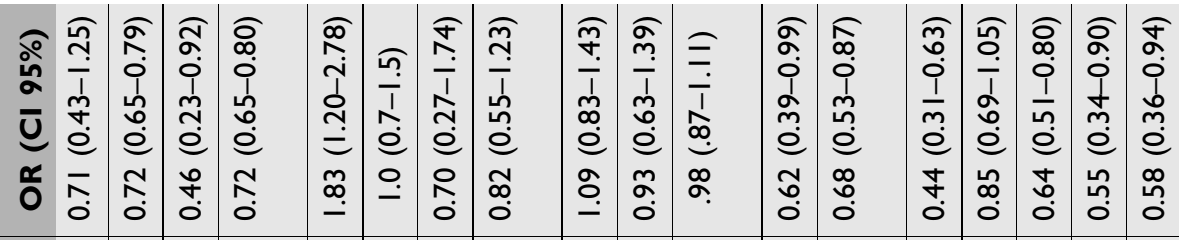

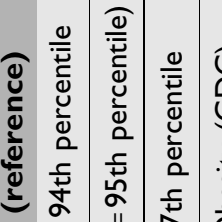

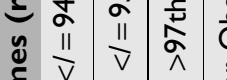

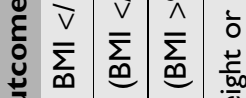

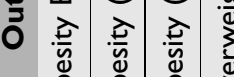

愛

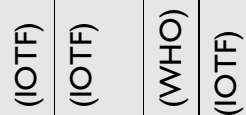

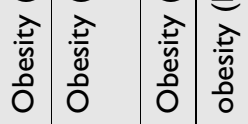

g

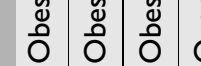

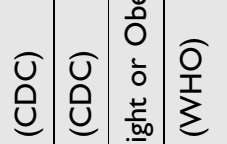

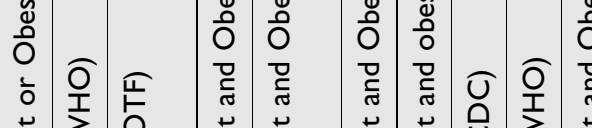

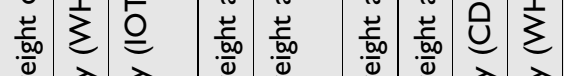

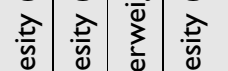

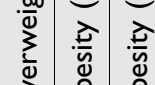

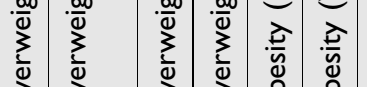

Oे

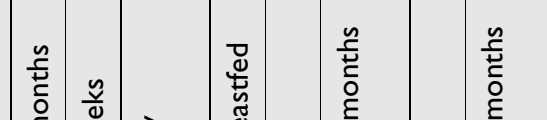

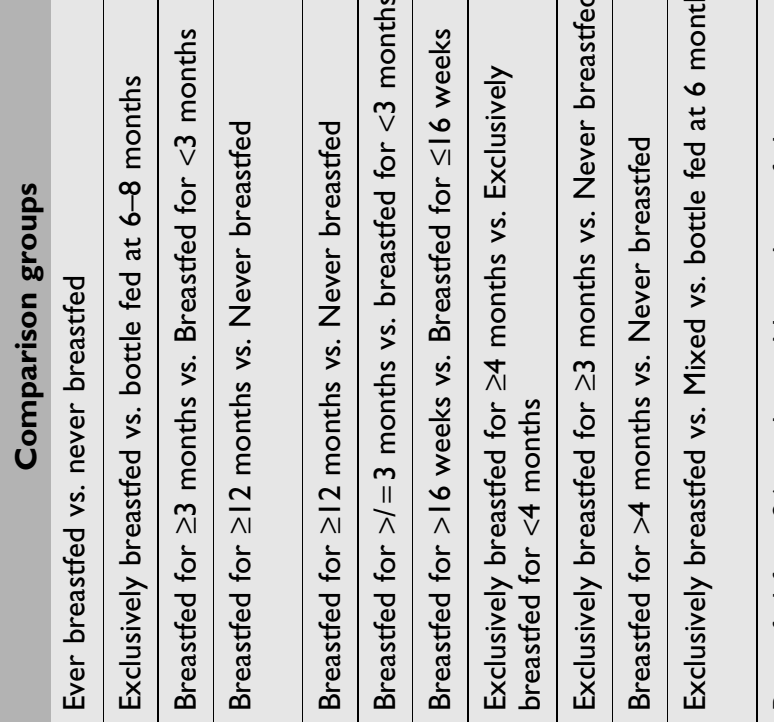

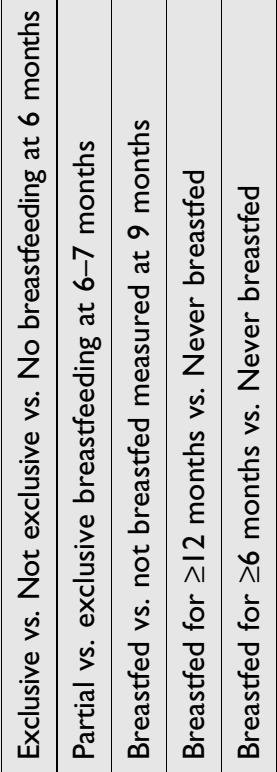

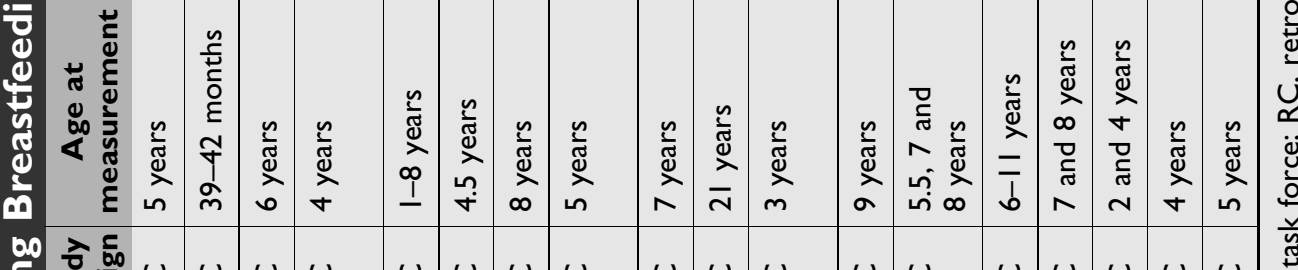

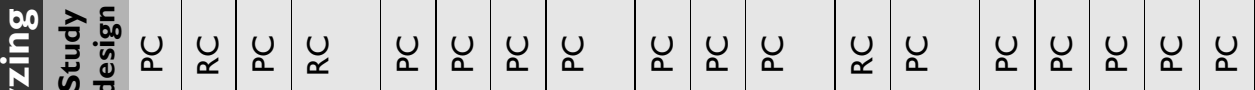

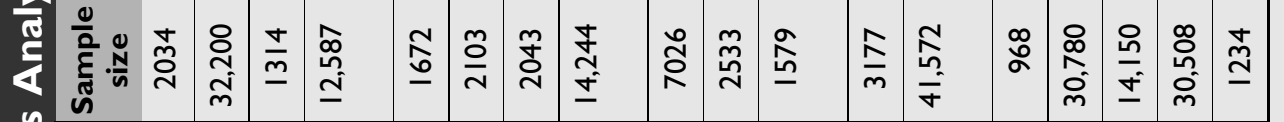

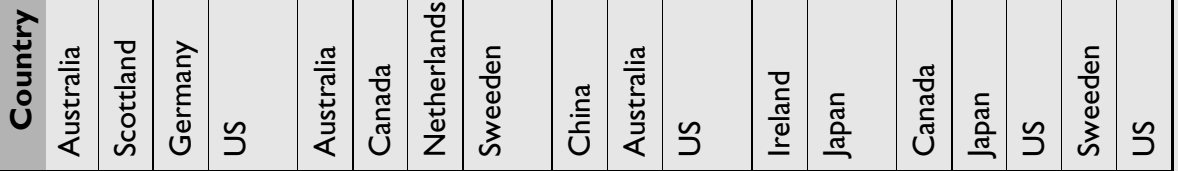

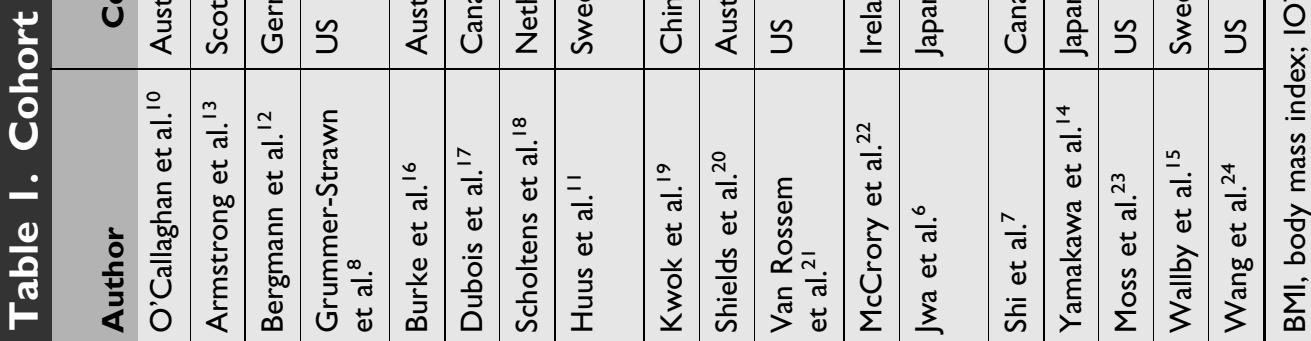


non-nutritive foods). ${ }^{37}$ The duration of full breastfeeding was noted until the date bottle-feeding was first introduced. Any Breastfeeding (ABF) is the duration of lactation. The analysis of breastfeeding duration was used as a continuous quantitative variable measured as days that mother spent: $\mathrm{EBF}, \mathrm{FBF}$, and $\mathrm{ABF}$.

\section{Child's Overweight and Obesity Status}

Anthropometric measurements, obtained from wellchild examinations, included weight and height. To weigh and measure children, standardized measurement procedures were used with the following equipments: $<2$ years: baby scale SECA 717 (to the nearest $2 \mathrm{~g}$ ) with measuring rod 231 (to the nearest $1 \mathrm{~mm}$ ) and $>2$ years: flat scale SECA 872 (to the nearest $50 \mathrm{~g}$ ) and mobile stadiometer SECA 217 (to the nearest $1 \mathrm{~mm}$ ).

BMI was calculated using the following formula: weight $(\mathrm{kg}) /$ height $(\mathrm{m})^{2}$. Childhood excess weight and obesity was defined using child growth standards established by the WHO. Using this measure, childhood excess weight is defined as BMI > one standard deviation body mass index (BMI) for age and sex, overweight is defined as values between 1 and 2 standard deviations BMI for age and sex, and obesity defined as BMI > two standard deviations BMI for age and sex. ${ }^{38}$

\section{Covariates}

The following sociodemographic and exposure factors studied were obtained from GP: sex, birth weight, weight gain in first year of life, maternal age, pregestational maternal BMI, mother's alcohol consumption during pregnancy (during 2nd-3rd trimester), and smoking during early pregnancy and 1-year postpartum. In addition, nationality (native/foreign), parental education level (no education-primary/secondary/university), family income in euros $(€)$ per month $(<800 / 800-1500 € / 1501-2500 € /$ $>2500 €)$, and maternal employment type during periconceptional period were studied.

\section{Statistical Analysis}

The data analysis was computed utilizing the Statistical Package for the Social Sciences version 21(SPSS, Chicago, IL) ${ }^{39}$ and the mgev R package. First, univariate analyses were performed. To obtain predictor variables, the comparisons of all variables with excess weight and obesity were made using Chi-squared tests, ANOVA test, Pearson's correlation, and Spearman's rho correlation. Significant results are reported alongside descriptive statistics in Table 2. A log-linear regression analysis was performed, in which the outcome variable was BMI at 6 years old. Analyses included variables that were significantly $(p<0.05)$ associated with excess weight or obesity in the univariate analyses at age 6 . We use Generalized Additive Models (GAMs) to identify complex nonlinear relationships between the response and explanatory vari- ables. ${ }^{40}$ Using results from the GAM model, we used an ordinal logistic regression to model the nonlinear relationship between variables. For both the log-linear regression and ordinal logistic regressions, we utilized 192 participants for whom we had responses for all variables and anthropomorphic measurements. We found no statistically significant differences in socioeconomic status (SES), "Full breastfeeding" and mother pregestational BMI between this group and those lost during the follow-up. Effects were considered statistically significant with $p$-value $<0.05$ and ORs with a $95 \%$ CI that did not include 1 .

\section{Results}

The median duration of FBF was 63.5 days and $21 \%$ of children were FBF at least 6 months. The prevalence of $\mathrm{ABF}$ at 12 months was $19.2 \%$. At 6 years of age, $32.8 \%$ and $17.7 \%$ of children were categorized as being of excess weight and obesity, respectively. Descriptive statistics of sociodemographic variables are shown in Table 2. Children who had high weight gain in their first year of life and whose mothers who had higher BMI, smoked, or drank alcohol during pregnancy, parents with low educational attainment were more likely to be of excess weight than those who didn't have these factors. Children who were exclusive or full breastfed were less likely to be of excess weight or obese at this age in the univariate analysis.

Predictors variables of BMI in children aged 6 years by log-linear regression are shown in Table 3. Pregestational maternal log BMI $\left(\mathrm{kg} / \mathrm{m}^{2}\right)\left(R^{2}=0.127, p<0.01\right)$; full breastfeeding (weeks) $R^{2}=-0.035, p<0.01$ ); infant weight gain $(\mathrm{kg})\left(R^{2}=0.348, p<0.01\right)$; and maternal alcohol consumption during pregnancy (g/day) $\left(R^{2}=0.266, p<0.01\right)$ were found to be predictive of excess weight at age 6 .

Figure 1 shows results from GAM model that analyzed linear trends or functional relationship between log BMI and four variables. Maternal pregestational BMI, infant weight gain, and maternal consumption were found to have a nonlinear relationship ( $r$ or the smooth term $>2$ ). Because of this a multivariate ordinal logistic analysis was conducted and results can be seen in Table 4. An increase in full breastfeeding (expressed in weeks) was associated with a decrease in overweight/obese of -0.052 (95\% CI, -0.10 to -0.003$)$. Maternal BMI and weight gain in the first year of life were also associated with an increase in overweight/obese of 0.093 (95\% CI, 0.023 to -0.163$)$ and .407 (95\% CI, 0.172 to -0.642 ), respectively. Family income and parental education were not statistically significant in this model. However, it is observed an inverse relationship between level of income at birth and average BMI at 6 years old. In our study, $12 \%$ of children belong to families living in relative poverty in 2009; and the proportion of obese is significantly higher among the poor $(33.3 \%)$ than rich individuals $(11.5 \%)$. While not significant, we observed a growing risk of high BMI as income declines. 


\section{Table 2. Descriptive Statistics of Study Sample}

Variable

Child BMI at 6 years

Obesity status at 6 years

\begin{tabular}{|c|c|c|c|c|c|c|}
\hline Normal weight & 156 & $(67.5)$ & n.a. & n.a. & n.a. & n.a. \\
\hline Overweight & 35 & $(15.2)$ & n.a. & n.a. & n.a. & n.a. \\
\hline Obese & 40 & $(17.3)$ & n.a. & n.a. & n.a. & n.a. \\
\hline EBF (weeks) ${ }^{b}$ & 324 & n.a. & $7.56(6.55-8.58)$ & $-0.16,0.01$ & n.a. & $-0.04(-0.07$ to -0.01$)$ \\
\hline FBF (weeks) ${ }^{b}$ & 324 & n.a. & II.64 (10.45-12.84) & $-0.17,<0.01$ & n.a. & $-0.04(-0.06$ to -0.01$)$ \\
\hline ABF (weeks) & 323 & n.a. & $27.96(25.45-30.46)$ & $0.02,0.76$ & n.a. & \\
\hline Sex of child & 324 & & & & 0.24 & \\
\hline Male & & $177(54.7)$ & n.a. & n.a. & & n.a. \\
\hline Female & & $147(45.3)$ & n.a. & n.a. & & n.a. \\
\hline Birth weight (g) & 324 & n.a. & $3270(3230-3320)$ & $0.10,0.14$ & n.a. & n.a. \\
\hline Weight gain first year $(\mathrm{kg})^{\mathrm{b}}$ & 287 & n.a. & $6.86(6.7 I-7.0 I)$ & $0.26,0.01$ & n.a. & $0.48(0.24-0.72)$ \\
\hline Maternal origin & 324 & & & & 0.52 & \\
\hline Native born & & $262(8 \mathrm{I})$ & n.a. & n.a. & & n.a. \\
\hline Foreign born & & $62(19)$ & n.a. & n.a. & & n.a. \\
\hline Maternal age $(y)$ & 324 & n.a. & $31.57(31.00-32.14)$ & $-0.06,0.34$ & n.a. & n.a. \\
\hline Maternal Pre-Gestational BMI ${ }^{\mathrm{b}}$ & 219 & n.a. & $24.59(23.96-25.23)$ & $0.26,<0.01$ & n.a. & $0.48(0.24-0.72)$ \\
\hline \multicolumn{7}{|l|}{ Maternal smoking } \\
\hline Periconceptional ${ }^{b}$ & 324 & & & & & \\
\hline Smoking & & $204(63.0)$ & n.a. & n.a. & 0.03 & $0.69(0.06-1.32)$ \\
\hline Not Smoking & & $120(37.0)$ & n.a. & n.a. & n.a. & n.a. \\
\hline Cigarettes/week & & n.a. & $27.90(22.66-33.13)$ & $0.20,<0.01$ & n.a. & $0.01(0.00-0.02)$ \\
\hline Postnatal (I year) ${ }^{\mathrm{b}}$ & 323 & & & & & \\
\hline Smoking & & $84(26.0)$ & n.a. & n.a. & 0.01 & $0.88(0.19-1.58)$ \\
\hline Not smoking & & $239(74.0)$ & n.a. & n.a. & n.a. & n.a. \\
\hline Cigarettes/week & & n.a. & $12.79(9.55-16.04)$ & $-0.06,0.67$ & n.a. & n.a. \\
\hline Maternal alcohol intake (Pregnancy) ${ }^{\mathrm{b}}$ & 324 & & & & 0.16 & \\
\hline Yes & & 37 ( 11.4$)$ & $5.09(3.24-6.94)$ & n.a. & & n.a. \\
\hline No & & $287(88.6)$ & & n.a. & & n.a. \\
\hline Alcohol (Grams/Day) & & n.a. & & $0.23,<0.01$ & & $0.21(0.09-0.32)$ \\
\hline Maternal Occupation & 324 & & & & 0,15 & \\
\hline outside the home & & $158(48.9)$ & n.a. & n.a. & & n.a. \\
\hline at home & & $165(51.1)$ & n.a. & n.a. & & n.a. \\
\hline Education level: Mother ${ }^{b}$ & 324 & $70(21.6)$ & n.a. & $-0.17,0.01$ & 0.05 & Ref \\
\hline None/Primary & & $154(47.5)$ & n.a. & & & $-0.13(-0.93$ to \\
\hline Secondary & & & n.a. & & & $0.67)$ \\
\hline University & & $100(30.9)$ & & & & $-0.86(-1.75$ to -0.02$)$ \\
\hline Education level: Father ${ }^{b}$ & 324 & & & $-0.19,<0.01$ & 0.04 & \\
\hline
\end{tabular}


Table 2. Descriptive Statistics of Study Sample continued

\begin{tabular}{|c|c|c|c|c|c|c|}
\hline Variable & $\mathbf{n}$ & $\mathbf{N}(\%)$ & Mean (Cl 95\%) & $\begin{array}{c}\text { Correlations } \\
\text { p-value }\end{array}$ & $\begin{array}{c}\text { ANOVA } \\
\text { t-test }\end{array}$ & $\begin{array}{c}\text { RR (Cl 95\%) } \\
\text { univariate }\end{array}$ \\
\hline None/primary & & $93(29.8)$ & n.a. & & & Ref \\
\hline Secondary & & $144(46.2)$ & n.a. & & & $-0.37(-1.01$ to 0.34$)$ \\
\hline University & & $75(24.0)$ & n.a. & & & $-1.08(-1.96$ to -0.24$)$ \\
\hline Family net income (€/month) & 323 & & & $-0.26,<0.01$ & $<0.01$ & \\
\hline$<800$ & & $38(11.8)$ & n.a. & & & $\mathrm{I} .64(0.46-2.8 \mathrm{I})$ \\
\hline $800-1499$ & & $124(38.4)$ & n.a. & & & $1.31(0.50-2.13)$ \\
\hline $1500-2500$ & & $93(28.8)$ & n.a. & & & $0.61(-0.22$ to I.44) \\
\hline$>2500$ & & $68(21.1)$ & n.a. & & & Ref \\
\hline
\end{tabular}

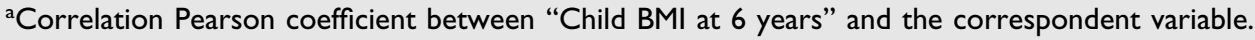

${ }^{b} p<0.05$ for excess weight and obesity at 6 years old in univariate analysis. Ref = Category used as reference for RR. Univariate statistics used include Chi-Squared tests, Pearson's Correlation, Spearman's Correlation, ANOVA, $t$-test to obtain predictor variables.

$A B F$, any breastfeeding; $E B F$, exclusive breastfeeding; $F B F$, full breastfeeding; n.a., not applicable; RR, relative risk.

\section{Discussion}

Our study shows that childhood obesity is a significant public health concern in the Region of Murcia: 1/3 of children had excess weight, similar to other results in this region. ${ }^{41}$ We observed a small, yet statistically significant, protective effect of FBF on obesity in 6-year-old children. A reduction of $3.5 \%$ of BMI in 6-year-old children by each week increase of FBF was observed, while the other variables in the model are held constant. More complex is the interpretation of ordinal regression model coefficients. Case of FBF, one week increase in FBF resulted in a 5.2\% decrease in the ordered log-odds of being in a higher BMI category, while the other variables in the model are held constant. The protective dose-response effect of breastfeeding on overweight or obesity is observed even for relatively short periods of breastfeeding. In addition, maternal BMI, children's weight gain in the first year of life, and exposure to alcohol and poverty increase the risk of excess weight and/or obesity later in childhood.

\section{Table 3. Log-Linear Regression of Body Mass Index with Predictor Variables} in Children Aged 6 Years

\begin{tabular}{|c|c|c|c|}
\hline Predictor variable & Regression coefficient & $95 \%$ confidence interval & p value \\
\hline Exclusive BF (weeks) & 0.021 & -0.028 to 0.070 & 0.44 \\
\hline FBF (weeks) & -0.035 & -0.065 to -0.006 & 0.01 \\
\hline Any BF (weeks) & 0.007 & -0.007 to 0.028 & 0.28 \\
\hline Maternal BMI $\left(\mathrm{kg} / \mathrm{m}^{2}\right)$ & 0.127 & $0.058-0.197$ & $<0.01$ \\
\hline Infant weight gain $(\mathrm{kg})$ & 0.348 & $0.072-0.624$ & 0.01 \\
\hline Alcohol consumption during pregnancy (g/d) & 0.266 & $0.123-0.408$ & $<0.01$ \\
\hline Mother smoking during periconceptional (cig/w) & 0.004 & -0.005 to 0.013 & 0.41 \\
\hline Mother smoking (dichotomous) & -0.191 & -1.314 to 0.933 & 0.74 \\
\hline Mother education & -0.004 & -0.604 to 0.596 & 0.99 \\
\hline Father education & 0.186 & -0.368 to 0.739 & 0.51 \\
\hline Net income & -0.396 & -0.860 to 0.068 & 0.09 \\
\hline
\end{tabular}

End Point: BMI (6 years) $r^{2}=0.261$, Durbin-Watson $=2.15$.

The following predictor variables were included: Maternal BMI, Infant weight gain ( $\mathrm{kg}$ ), mother smoking during periconceptional (dichotomous and cig/week) periods, Exclusive BF, ABF and FBF, mother and father educational level (ordinal), net income per month (ordinal), Infant weight gain and alcohol intake during pregnancy (g/day). To obtain predictor variables the comparisons of all variables were made using the unpaired Student's $t$ test, ANOVA test and Pearson/Spearman's rho correlation. 

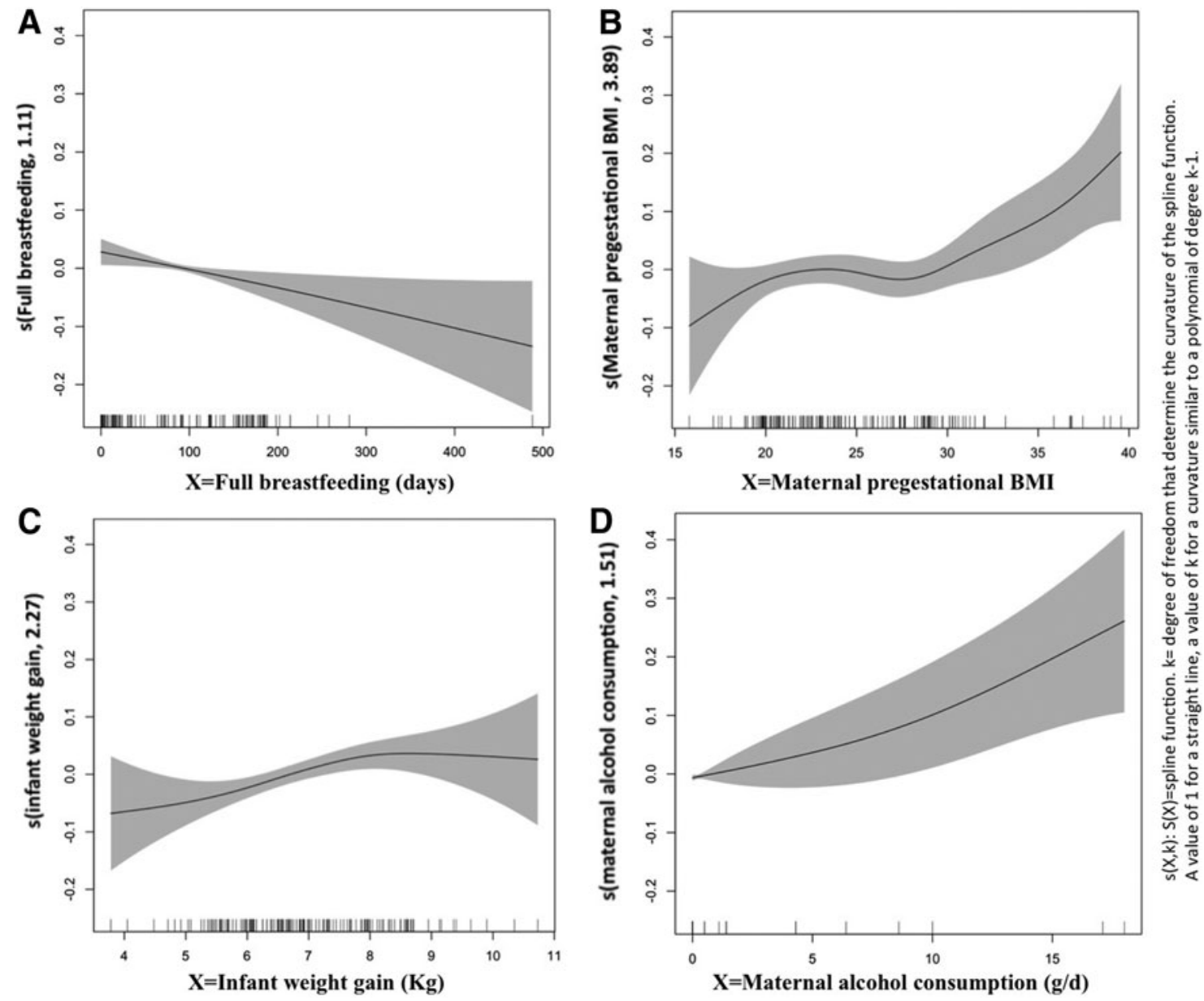

FIG. 1. GAMs to identify the form of the functional relationship between the log BMI at 6 years and the explanatory variables. (A) There is a linear relationship with full breastfeeding $(r=1)$; There is a nonlinear relationship $(r>/=2)$ with $(\mathrm{B})$ maternal pregestational BMI $(\mathrm{C})$ infant weight gain and (D) maternal alcohol consumption. BMI, body mass index; GAM, generalized additive model.

The benefits of breastfeeding on both child and maternal health are well known. In US Surgeon General's Call to Action to support breastfeeding, it is noted that late weaning is associated with a protective effect in children against infections, eczema, hospitalization, SIDS, and chronic diseases such as leukemia, type 2 diabetes, asthma, and obesity. ${ }^{42}$ The WHO also found significant association between the duration of breastfeeding and type 2 diabetes, cholesterol, and performance in intelligence tests. ${ }^{43}$ In their analysis, they suggest that there is a small reduction in prevalence in childhood weight gain $(10 \%)$ in children exposed to longer durations of breastfeeding, but warn about lack of adjustments for confounding factors which may attribute to this effect. ${ }^{43}$ Research conducted throughout various countries have yielded inconclusive results regarding the protective effects of breastfeeding on childhood adiposity. ${ }^{6-8,10-24}$

In the study, maternal BMI was significantly associated with BMI, overweight and obesity in 6-year-old children. Our findings are consistent with previous literature that identifies maternal obesity status as an important factor in childhood $^{11,15,17}$ and adulthood ${ }^{20}$ BMI. Mechanisms explaining this relationship include inheritance of genes that make child susceptible to excess weight, mother's role in shaping eating habits and activity environment, and the effects of maternal obesity as a fetal modulating environmental factor during pregnancy. ${ }^{44,45}$ Intrauterine environment can alter metabolism through changes in gene expression. ${ }^{46}$

Our results found that prolonging the introduction of formula feeding decreased the risk of excessive weight and obesity. We utilized variables that have been standardized by the WHO for both obesity and breastfeeding. We observed significant results with $\mathrm{FBF}$, a variable that is a more realistic measure than exclusive breastfeeding, which is more demanding and difficult to get practice by definition. However, we did not observe a similar significant effect with ABF. The use of a standardized definition for breastfeeding is critical to evaluate the relationship between breastfeeding and obesity on an international scale. While the effect of 1 day of FBF was small, it was significant in providing an immediate and accumulative protective effect. The effect of breastfeeding on obesity has been studied in cohorts ranging from 2 years $^{23}$ to 21 years ${ }^{20}$ and a protective effect has been observed up to $6-$ 11 years. ${ }^{7}$ Most of the studies analyzing breastfeeding and 
Table 4. Ordinal Regression: Risk Factors Associated with Overweight/Obesity at 6 Years

\begin{tabular}{|c|c|c|c|c|c|}
\hline \multirow[b]{2}{*}{ Variable } & \multirow[b]{2}{*}{ Wald } & \multirow[b]{2}{*}{ Significance } & \multirow[b]{2}{*}{ Regression coefficient } & \multicolumn{2}{|c|}{ Cl $95 \%$} \\
\hline & & & & Min & $\operatorname{Max}$ \\
\hline EBF (weeks) & 0.912 & 0.34 & 0.027 & -0.29 & 0.083 \\
\hline FBF (weeks) $)^{a}$ & 4.151 & 0.04 & -0.052 & -0.10 & -0.003 \\
\hline ABF (weeks) & 2.626 & 0.11 & 0.015 & -0.003 & 0.032 \\
\hline Maternal BMI $\left(\mathrm{Kg} / \mathrm{m}^{2}\right)$ & 6.791 & $<0.01$ & 0.093 & 0.023 & 0.163 \\
\hline Weight gain first year of life $(g)^{a}$ & 5.731 & 0.01 & 0.407 & 0.172 & 0.642 \\
\hline Alcohol intake during pregnancy (g/d) & 3.637 & 0.05 & 0.136 & 0.024 & 0.236 \\
\hline Periconceptional maternal smoking (cig/week) & 0.001 & 0.97 & 0.003 & -0.003 & 0.009 \\
\hline Monthly net income $<800 €$ & 1.592 & 0.17 & 1.173 & -0.594 & 2.739 \\
\hline $800-1499 €$ & 1.149 & 0.28 & 0.575 & -0.597 & 2.039 \\
\hline $1500-2500 €$ & 0.383 & 0.53 & 0.051 & -0.881 & 1.560 \\
\hline Maternal University Education (Yes/No) & 0.134 & 0.71 & -0.160 & -1.020 & 0.700 \\
\hline Paternal University Education (Yes/No) & 0.007 & 0.93 & -0.036 & -0.907 & 0.835 \\
\hline
\end{tabular}

${ }^{a} p<0.05$.

obesity utilize dichotomous variables. ${ }^{7,12,13,17,18,21,23,24,47,48}$ Our results are consistent with multiple studies that have found significant inverse associations between breastfeeding type and duration and child's weight status. ${ }^{6,8,14-16,22}$ However, some studies have found nonsignificant associations between breastfeeding and childhood overweight. ${ }^{11,19,20}$ These differences in results may be attributed to cultural differences in the population analyzed, differences in definitions of breastfeeding, obesity, and covariates, and also differences in age at which BMI was measured.

In our study, periconceptional and postnatal smoking was significantly associated with excess weight in the univariate analysis. Exposure to smoking during pregnancy has been associated with childhood overweight and correlated with child obesity, although the biological mechanism for this epidemiological link is not fully understood. ${ }^{15,17,49}$ Maternal smoking is related to low birth weight, which is associated with catch-up growth early in life, which is associated with overweight and obesity in childhood. ${ }^{12,17}$ Mothers who smoke during pregnancy are more likely to be less educated and not breastfeed than nonsmoking mothers. ${ }^{11,14,29,30,49}$ Exposure to nicotine in utero has been associated with increased body fat and weight. ${ }^{50}$ Maternal smoking in pregnancy has also been suggested to affect the appetite regulation system in the developing brain, making it a possible independent risk factor for overweight in children and can be a proxy for other environmental factors present during postnatal development such as diet and physical activity. ${ }^{49} \mathrm{We}$ also found a significant association between increased maternal alcohol consumption during pregnancy and increased childhood BMI. While maternal smoking during pregnancy is studied as a risk factor for child obesity, the ef- fects of alcohol consumption on weight outcomes are not as scrutinized. ${ }^{47,49}$ Evidence is available showing that children with partial fetal alcohol syndrome experience higher overweight and obesity rates. ${ }^{51}$ Animal studies, demonstrate that prenatal alcohol exposure leads to insulin resistance and leads to glucose intolerance. ${ }^{52}$ Similar to our study, it is important for future studies to evaluate the interaction between smoking and alcohol consumption for better understanding of their impact on childhood obesity.

Also, our findings showed an association between weight gain in the first year and childhood BMI and excess weight at 6 years old. In a systematic review that analyzed rapid infancy weight gain and subsequent obesity, 21 studies reported a significant positive association. ${ }^{53} \mathrm{Du}-$ Bois' cohort study found that weight gain in the first 5 months was associated with overweight at 4.5 years. ${ }^{17}$ Although there is noted effect of early infant weight gain on childhood BMI, results were not as consistent with other measures of adiposity such as skinfold thickness. ${ }^{21}$ Rapid weight gain in the first two years of life has been linked to obesity, particularly in infants with low birth weight and size (Perng). Although weight gain in the first year of life as part of "catch-up growth" is associated with adverse metabolic effects, there may also be certain benefits to this type of growth in certain groups. ${ }^{54}$ The mechanism explaining how early infant weight gain influences weight status later on in life is unclear. However, it is well understood that early development not only is extremely susceptible to environmental influences but also is influential in later health outcomes. ${ }^{55}$ Infant weight change in the first 6 months of life is associated with both breastfeeding and childhood BMI. ${ }^{21}$ One possible interaction between breastfeeding and weight gain in the first year of 
life can be explained by differing levels of protein content with breastfeeding and formula feeding. ${ }^{56}$ In a study conducted in five European countries, they found that high protein intake induced increased weight gain velocity during the first months of life, resulting in increased body fat deposition. ${ }^{57}$

Although we observed in the univariate analysis a relationship of parental education levels on childhood overweight and obesity, the effect was not seen in the multivariable regressions. Previous studies have analyzed the effects of parental education and its effect on obesity at different ages. While maternal education was found to have a significant effect on childhood obesity, ${ }^{12,14,16,20,21}$ fewer studies considered paternal education. ${ }^{6}$ Occupational status was also analyzed in previous studies, but differed in the way it was measured. ${ }^{12,19}$ In a Swedish study, they found that maternal employment for less than 3 months during pregnancy was associated with short-term breastfeeding. ${ }^{11}$ Our study assessed the activity level associated with maternal occupation, but did not find a difference between mother's occupation and risk of childhood excess weight and obesity at 6 years old.

We found the economic level of the families to be associated with BMI in children but only in the univariate analysis. Socioeconomic disparities are a considerable risk factor for obesity and the abandonment of breastfeeding. ${ }^{31}$ Children of low SES are more likely to be obese than highSES children and their rates of obesity are increasing at a much faster rate. ${ }^{58}$ This is particularly important to analyze in Murcia, which is the region with the 5th lowest GDP per capita in Spain. ${ }^{59}$

Extensive information gathered regarding breastfeeding during infancy, before outcomes were measured, allows us to have detailed information about child's feeding habits. Multiple follow-up sessions took place both over the phone and face-to-face about breastfeeding habits, particularly in the first two years of life. By treating each type of breastfeeding and its duration in a continuous manner, using days as unit of measurement, we have data on the exact timing that infants were introduced to bottle feeding at home. The careful and exhaustive data collection on BF minimizes the likelihood of recall bias in the study.

Several limitations must be considered in our study. First, the sample size was limited compared with that of previous studies. Secondly, it is important to consider both recall and selection bias. We have attempted to compensate these limitations by contacting participants with increased frequency to retrieve more accurate information and decrease bias. Our extensive data collection provided us with results that are largely consistent with the rest of the literature. Attrition during follow-up created loss of growth data and maternal BMI limiting the number of participants with completed records in parts of the analysis. Previous studies have noted similar limitations regarding loss of data and high attrition rates in longitudinal studies. ${ }^{14,15,20}$ Finally, a common limitation of observational studies is the inability to adjust for all confounding variables. . $^{6,8,13,14,19,21}$
However, the covariables discussed in this study are representative of some of the major underlying risk factors for obesity considered in previous studies. There are some factors, such as heredity and lifestyle factors (diet, physical activity, time spent watching TV/playing computer games/ sleep), that were not analyzed in this study. In future studies, we will incorporate some of these variables. Besides, we will conduct a developmental assessment of these children at 8 and 12 years old.

Analysis of overweight and obesity could have been improved by using other effective methods to measure adiposity along with BMI. Both X-ray absorptiometry ${ }^{21}$ and skinfold thickness ${ }^{12,21,49}$ have been suggested and used to better analyze the relationship between breastfeeding and obesity. Nevertheless, BMI is still considered an inexpensive and noninvasive way to measure body fat that is internationally accepted..$^{9,60}$

\section{Conclusions}

In our study, we established a dose-dependent relationship between FBF duration and weight status in early childhood. The early introduction of bottle feeding increased risk for childhood excess weight and obesity. The use of standardized measures, particularly of breastfeeding, will go a long way in better understanding this protective effect internationally. While evidence is still being gathered on this topic, prevention programs against childhood obesity should promote prolonged breastfeeding, the creation of healthier environments during pregnancy, and infancy free of tobacco and alcohol and consider antipoverty interventions.

\section{Acknowledgments}

This work was supported by Mount Sinai International Exchange Program for Minority Students (grant MD001452) from the National Center on Minority Health and Health Disparities of the U.S. National Institutes of Health; and the Nacer \& Crecer sin OH Program Regional Coordination of DG Public Health and Drug Addiction, The Regional Ministry of Health, Murcia, Spanish National Plan on Drugs, Ministry of Health, Social Services and Equality, Madrid, Spain. The authors also thank Programa de Ayudas a Grupos de Excelencia de la Región de Murcia, Fundación Séneca (\#19884-GERM-15) and MINECO/ FEDER (ECO-2015-65758-P).

\section{Author Disclosure Statement}

No competing financial interests exist.

\section{References}

1. World Health Organization. Obesity: Preventing and Managing the Global Epidemic. World Health Organization: Geneva, 2000 . 
2. Yu Z, Han S, Chu J, et al. Trends in overweight and obesity among children and adolescents in China from 1981 to 2010: A metaanalysis. PLoS One 2012; 7:e51949.

3. Livingstone M. Childhood obesity in Europe: A growing concern. Public Health Nutr 2001;4:109-116.

4. Wijnhoven TM, van Raaij JM, Yngve A, et al. WHO European Childhood Obesity Surveillance Initiative: Health-risk behaviours on nutrition and physical activity in 6-9-year-old schoolchildren. Public Health Nutr 2015;18:3108-3124.

5. Ramiro-González MD, Sanz-Barbero B, Royo-Bordonada MÁ. Childhood Excess Weight in Spain From 2006 to 2012. Determinants and Parental Misperception. Rev Esp Cardiol (Engl Ed) 2017;70:656-663.

6. Jwa SC, Fujiwara T, Kondo N. Latent protective effects of breastfeeding on late childhood overweight and obesity: A nationwide prospective study. J Obes 2014;22:1527-1537.

7. Shi Y, de Groh M, Morrison H. Perinatal and early childhood factors for overweight and obesity in young Canadian children. Can J Public Health 2013;104:69-74.

8. Grummer-Strawn LM, Mei Z. Does breastfeeding protect against pediatric overweight? Analysis of longitudinal data from the Centers for Disease Control and Prevention Pediatric Nutrition Surveillance System. Pediatrics 2004;113:e81-e86.

9. Chan RS, Woo J. Prevention of overweight and obesity: How effective is the current public health approach. Int J Environ Res Public Health 2010;7:765-783.

10. O'Callaghan M, Williams G, Andersen M, et al. Prediction of obesity in children at 5 years: A cohort study. J Paediatr Child Health 1997;33:311-316.

11. Huus K, Ludvigsson JF, Enskär K, et al. Exclusive breastfeeding of Swedish children and its possible influence on the development of obesity: A prospective cohort study. BMC Pediatr 2008;8:42.

12. Bergmann KE, Bergmann R, Von Kries, et al. Early determinants of childhood overweight and adiposity in a birth cohort study: Role of breast-feeding. Int J Obes 2003;27:162-172.

13. Armstrong J, Reilly JJ. Breastfeeding and lowering the risk of childhood obesity. Lancet 2002;359:2003-2004.

14. Yamakawa M, Yorifuji T, Inoue S, et al. Breastfeeding and obesity among schoolchildren: A nationwide longitudinal survey in Japan. JAMA Pediatr 2013;167:919-925.

15. Wallby T, Lagerberg D, Magnusson M. Relationship between breastfeeding and early childhood obesity: Results of a prospective longitudinal study from birth to 4 years. Breastfeed Med 2017;12: 48-53.

16. Burke V, Beilin LJ, Simmer K, et al. Breastfeeding and overweight: Longitudinal analysis in an Australian birth cohort. $\mathrm{Pe}$ diatrics 2005;147:56-61.

17. Dubois L, Girard M. Early determinants of overweight at 4.5 years in a population-based longitudinal study. Int J Obes 2006;30:610-617.

18. Scholtens S, Gehring U, Brunekreef B, et al. Breastfeeding, weight gain in infancy, and overweight at seven years of age: The prevention and incidence of asthma and mite allergy birth cohort study. Am J Epidemiol 2007;165:919-926.

19. Kwok MK, Schooling CM, Lam TH, e al. Does breastfeeding protect against childhood overweight? Hong Kong's 'Children of 1997'birth cohort. Int J Epidemiol 2009;39:297-305.

20. Shields L.; Mamun AA, O'Callaghan M, et al. Breastfeeding and obesity at 21 years: A cohort study. J Clin Nurs 2010;19:16121617.

21. van Rossem L, Vogel I, Steegers E. Moll, et al. Breastfeeding patterns among ethnic minorities: The Generation R Study. $J$ Epidemiol Community Health 2010;64:1080-1085.
22. McCrory C, Layte R. Breastfeeding and risk of overweight and obesity at nine-years of age. Soc Sci Med 2012;75:323-330.

23. Moss BG, Yeaton WH. Early childhood healthy and obese weight status: Potentially protective benefits of breastfeeding and delaying solid foods. Matern Child Health J 2014;18:1224.

24. Wang L, Collins C, Ratliff M, et al. Breastfeeding reduces childhood obesity risks. Child Obes 2017;13:197-204.

25. Bartok CJ, Ventura AK. Mechanisms underlying the association between breastfeeding and obesity. Int J Pediatr Obes 2009;4: 196-204.

26. Savino F, Liguori SA, Fissore MF, et al. Breast milk hormones and their protective effect on obesity. Int J Pediatr Endocrinol 2009; 2009:327505.

27. Verduci E, Banderali G, Barberi S, et al. Epigenetic effects of human breast milk. Nutrients 2014;6:1711-1724.

28. Fukuda S, Ohno H. Gut microbiome and metabolic diseases. Semin Immunopathol 2014;36:103-114.

29. Ortega-García JA, Pastor TE, Martínez LI, et al. Malama project in the Region of Murcia (Spain): Environment and breastfeeding. An Pediatr (Barc) 2008;68:447-453.

30. Ortega-García JA, Olano-Soler HA, Martínez-Álvarez A, et al. Breastfeeding duration and anogenital distance in 2-year-old infants. Breastfeed Med 2016;11:350-355.

31. Instituto Nacional de Estatistica. Population Figures at 1 January 2014 Migration Statistics 2013. Madrid, Spain. 2016. Available at www.ine.es/en/prensa/np854_en.pdf Last accessed July 3, 2017.

32. Ortega-García JA, Cárceles-Álvarez A, Cotton-Caballero A, et al. Environmental factors related with breastfeeding duration: A one year follow-up study. Acta Pediatr Esp 2015;73:97-103.

33. Ortega García JA, Sanchez Sauco MF, Jaimes Vega DC, et al Hoja verde durante el embarazo y lactancia materna. Available at http://pehsu.org/wp/wp-content/uploads/hoja_verde_reproductiva.pdf. Unidad de Salud Medioambiental Pediátrica. Murcia, Spain, 2013 Last accessed July 3, 2017.

34. Ortega García JA, Sanchez Sauco MF, Jaimes Vega DC, et al Manual de la Hoja Verde de Salud medioambiental Reproductiva. Creando ambientes más saludables durante el embarazo y lactancia. Unidad de Salud Medioambiental Pediátrica. Murcia, Spain, 2013. Available at http://pehsu.org/wp/wp-content/uploads/ MANUAL-DE-HOJA-VERDE.pdf Last accessed July 3, 2017.

35. Ministerio de Sanidad, Servicios Sociales e Igualdad. "Hoja Verde" en Consulta de enfermeria medioambiental, en parejas embarazadas de alto riesgo prenatal: Buenas practicas en la estrategia en atencion al parto y salud reproductivas de SNS. Madrid 2015.

36. Schor EL. Rethinking well-child care. Pediatrics 2004;114:210-216.

37. World Health Organization. Nutrition: The World Health Organization's Feeding Recommendation. Available at www.who.int/ nutrition/topics/infantfeeding_recommendation/en Last accessed June 20, 2017.

38. World Health Organization. Media Centre: Obesity and Overweight. Available at www.who.int/mediacentre/factsheets/fs311/en Last accessed June 20, 2017.

39. IBM Corp. IBM SPSS Statistics for Windows, Version 21.0. Armonk, NY, 2012.

40. Hastie T, Tibshirani R. Generalized Additive Models. Hoboken, NJ: Wiley Online Library, 1990.

41. Espín RM, Pérez FD, Sánchez RJ, et al. Prevalence of childhood obesity in the Murcia Region; an assessment of different references for body mass index. An Pediatr (Barc) 2013;78:374-381.

42. U.S. Department of Health and Human Services. The Surgeon General's call to action to support breastfeeding. Washington, DC: 
U.S. Department of Health and Human Services, Office of the Surgeon General, 2011.

43. Horta BL, Victora CG, Cesar G. Long-term effects of breastfeeding: A systematic review. Geneva, Switzerland: World Health Organization, 2013. www.who.int/maternal_child_adolescent/documents/ breastfeeding_long_term_effects/en/ (last accessed November 30, 2017).

44. Whitaker RC. Predicting preschooler obesity at birth: The role of maternal obesity in early pregnancy. Pediatrics 2004;114: e29-e36.

45. Chagnon YC, Rankinen T, Snyder EE, et al. The human obesity gene map: The 2002 update. J Obes 2003;11:313-367.

46. Oken E, Gillman MW. Fetal origins of obesity. $J$ Obes 2003;11: 496-506.

47. Gibson LY, Byrne SM, Davis EA, et al. The role of family and maternal factors in childhood obesity. Med J Aust 2007; 186:591.

48. Griffiths LJ, Smeeth L, Hawkins SS, et al. Effects of infant feeding practice on weight gain from birth to 3 years. Arch Dis Child 2009; 94:577-582.

49. Moschonis G, Grammatikaki E, Manios Y. Perinatal predictors of overweight at infancy and preschool childhood: The GENESIS study. Int J Pediatr Endocrino 2008;32:39-47.

50. Harris HR, Willett WC, Michels KB. Parental smoking during pregnancy and risk of overweight and obesity in the daughter. Int $J$ Obes 2013;37:1356-1363.

51. Fuglestad AJ, Boys CJ, Chang PN, et al. Overweight and obesity among children and adolescents with fetal alcohol spectrum disorders. Alcohol Clin Exp Res 2014;38:2502-2508.

52. Chen L, Nyomba B. Glucose intolerance and resistin expression in rat offspring exposed to ethanol in utero: Modulation by postnatal high-fat diet. Endocrinology 2003;144:500-508.

53. Ong KK, Loos RJ. Rapid infancy weight gain and subsequent obesity: Systematic reviews and hopeful suggestions. Acta Paediatr 2006;95:904-908.

54. Yeung M. Postnatal growth, neurodevelopment and altered adiposity after preterm birth-from a clinical nutrition perspective. Acta Paediatr 2006;95:909-917.
55. Hanson MA, Gluckman P. Early developmental conditioning of later health and disease: Physiology or pathophysiology? Physiol Rev 2014;94:1027-1076.

56. Heinig MJ, Nommsen LA, Peerson JM, et al. Energy and protein intakes of breast-fed and formula-fed infants during the first year of life and their association with growth velocity: The DARLING Study. Am J Clin Nutr 1993;58:152-161.

57. Escribano J, Luque V, Ferre N, et al. Effect of protein intake and weight gain velocity on body fat mass at 6 months of age: The EU Childhood Obesity Programme. Int J Obes 2012;36: 548-553.

58. Lee H, Andrew M, Gebremariam A, et al. Longitudinal associations between poverty and obesity from birth through adolescence. Am J Public Health 2014;104:e70-e76.

59. Instituto Nacional de Estatistica. Spanish Regional Accounts: Base 2010. Madrid, Spain, 2010. Available at www.ine.es/en/prensa/ np901_en.pdf Last accessed 30 June, 2017.

60. Centers of Disease Control. Body Mass Index: Considerations for Practitioners. Department of Health and Human Services, Atlanta, US, 2015 Available at www.cdc.gov/obesity/downloads/bmiforpac titioners.pdf Last accessed 20 June, 2017.

Address correspondence to: Juan Antonio Ortega-García, MD, PhD Paediatric Environmental Health Speciality Unit Laboratory of Environment and Human Health (A5)

Department of Paediatrics Institute of Biomedical Research IMIB Arrixaca Virgen de la Arrixaca University Hospital University of Murcia

Ctra. Madrid-Cartagena, $s / n$. El Palmar (Murcia) 30120 Spain

E-mail: ortega@pehsu.org 